\title{
Is obstructive sleep apnoea a comorbidity of COPD and is it involved in chronic systemic inflammatory syndrome?
}

\section{To the Editors:}

Last year, L.M. Fabbri and K.F. Rabe published a very interesting article entitled "From COPD to chronic systemic inflammatory syndrome?" [1].

In the article, the authors clearly illustrated that chronic obstructive pulmonary disease (COPD) is not only an inflammatory chronic disease of the airway and the lungs, but also involves systemic, cellular and humoral inflammation, as well as systemic oxidative stress, with striking changes in vasomotor and endothelial functions. These systemic effects of smoking-induced COPD are also critically implicated in establishing associated cardiovascular and metabolic disorders. The presence of frequent complex comorbidities led the authors to consider COPD to be a predisposing condition for developing a new distinct disorder, called chronic systemic inflammatory syndrome (CSIS). Thus, according to the authors, the diagnosis of CSIS needs to be confirmed by the presence of at least three components from a panel of the six most frequent comorbidities that provoke clinical and functional abnormalities of respiratory, cardiovascular and metabolic systems [1].

More recently, the same authors wrote an interesting review on the complex chronic comorbidities of COPD [2]. Of the frequent, complex, chronic comorbidities associated with COPD, we would like to highlight the important role of obstructive sleep apnoea (OSA), which actively participates in the development of CSIS. Important features of OSA are: a slow, progressive, severe evolution; the ability to impair, directly or indirectly, all target organs simultaneously; persistence, sustained by local and systemic inflammation; and association with clinically recognisable features, signs and symptoms. In addition, OSA shares several important features with COPD, as follows. 1) OSA affects $\leqslant 4-6 \%$ of all middleaged males and $2 \%$ of middle-aged females, with percentages similar to COPD [3]. 2) It is now appreciated by several wellcontrolled epidemiological studies that $\sim 20 \%$ of patients with OSA will have COPD [4], and $\sim 10 \%$ of OSA is disclosed in COPD patients independently of the degree of functional status [5]. 3) In $63 \%$ of OSA patients a history of smoking is recorded, which is a predisposing factor for both OSA and COPD [5]. 4) With regard to the cardiac and metabolic effects often reported in COPD, right cardiac failure and comorbidities in the left heart, including congestive failure and systemic hypertension, are often observed in OSA patients [6]. Associated metabolic abnormalities, such as dyslipidaemia, insulin resistance and obesity, are also commonly present in these patients [5], indicating that OSA is characterised by signs and symptoms leading to systemic, clinical and functional abnormalities. 5) In addition, OSA is characterised by the presence of upper airway and systemic inflammation: there is evidence that circulating, local inflammatory and oxidative stress factors are constantly increased in OSA patients [7, 8], while further recent studies reported a strongly positive correlation between C-reactive protein and severity of OSA [9]. The reason for increased inflammation in OSA is likely to be the activation of nuclear factor- $\kappa \mathrm{B}$ by stress hypoxia and/or increased adipokines and free fatty acids, which are released by excess adipose tissue and represent the final common inflammatory pathway linking obesity, OSA and the metabolic syndrome, both individually and, in many cases, synergistically [10]. 6) Finally, as regards the complications that modify the natural history of COPD, it has previously been shown that an augmented risk of developing respiratory failure, pulmonary hypertension and cor pulmonale exists in patients with OSA and COPD (overlap syndrome), compared with patients with only COPD, independently of the degree of airway obstruction [11].

For all these reasons, together with the evidence that both chronic obstructive pulmonary disease and obstructive sleep apnoea are more frequent among elderly individuals, we would like to stimulate discussion about the proposal to add obstructive sleep apnoea to the panel of the most frequent comorbidities and/or associations, which might seriously change the severity and prognosis of the newly coined chronic systemic inflammatory syndrome (table 1).

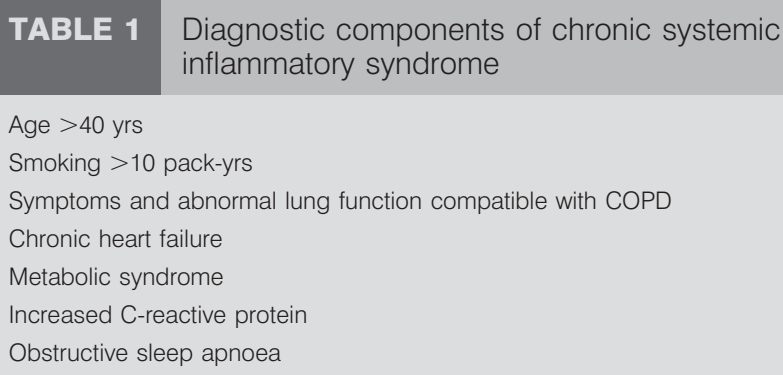

COPD: chronic obstructive pulmonary disease

\section{P. Carratu and O. Resta}

Dept of Pulmonary Medicine, University of Bari, Bari, Italy.

\section{STATEMENT OF INTEREST}

None declared.

\section{REFERENCES}

1 Fabbri LM, Rabe KF. From COPD to chronic systemic inflammatory syndrome? Lancet 2007; 370: 797-799. 
2 Fabbri LM, Luppi F, Beghé B, Rabe KF. Complex chronic comorbidities of COPD. Eur Respir J 2008; 31: 204-212.

3 Coughlin S, Calverley P, Wilding J. Sleep disordered breathing - a new component of syndrome $\mathrm{x}$ ? Obes Rev 2001; 2: 267-274.

4 Fletcher EC. Chronic lung disease in the sleep apnea syndrome. Lung 1990; 168: Suppl., 751-761.

5 Alam I, Lewis K, Stephens JW, Baxter JN. Obesity, metabolic syndrome and sleep apnoea: all pro-inflammatory states. Obes Rev 2007; 8: 119-127.

6 Kiely JL, McNicholas WT. Cardiovascular risk factors in patients with obstructive sleep apnoea syndrome. Eur Respir J 2000; 16: 128-133.

7 Lavie L. Obstructive sleep apnoea syndrome - an oxidative stress disorder. Sleep Med Rev 2003; 7: 35-51.
8 Carpagnano GE, Kharitonov SA, Resta O, FoschinoBarbaro MP, Gramiccioni E, Barnes PJ. Increased 8isoprostane and interleukin-6 in breath condensate of obstructive sleep apnea patients. Chest 2002; 122: 1162-1167.

9 Chung S, Yoon IY, Shin YK, et al. Endothelial dysfunction and C-reactive protein in relation with the severity of obstructive sleep apnea syndrome. Sleep 2007; 30: 997-1001.

10 Htoo AK, Greenberg H, Tongia S, et al. Activation of nuclear factor $\kappa \mathrm{B}$ in obstructive sleep apnea: a pathway leading to systemic inflammation. Sleep Breath 2006; 10: 43-50.

11 Chaouat A, Weitzenblum E, Krieger J, Ifoundza T, Oswald M, Kessler R. Association of chronic obstructive pulmonary disease and sleep apnea syndrome. Am J Respir Crit Care Med 1995; 151: 82-86.

DOI: $10.1183 / 09031936.00008008$ 